\title{
Terapia ocupacional nos contextos hospitalares: possibilidades e desafios da residência multiprofissional
}

\author{
Rosa Maria de Araujo Mitre \\ Doutora em Ciências, Área de Saúde da Criança e da Mulher, Pesquisadora, Instituto Fernandes Figueira, \\ Fundação Oswaldo Cruz - Fiocruz, Rio de Janeiro, RJ, Brasil
}

\begin{abstract}
Resumo: Esse artigo é decorrente de uma apresentação no Simpósio de Terapia Ocupacional em Contextos Hospitalares sobre o tema a pós-graduação no processo de formação e pesquisa na Terapia Ocupacional em Contextos Hospitalares. Sem pretensão de esgotar um tema tão amplo, escolhemos fazer um pequeno recorte sobre a residência multiprofissional. Pelo fato de ser uma experiência nova em termos de terapia ocupacional consideramos oportuno pensar sobre o impacto que ela pode ter não apenas na formação de novos profissionais, mas também na prática dos mais antigos. È importante pensar que se por um lado ela amplia possibilidades, por outra nos coloca desafios e a necessidade de refletir o que queremos: reproduzir modelos já existentes de atuação ou pensar novos modelos? Para isso, trazemos como exemplo dois dispositivos utilizados com os residentes para promover uma reflexão sobre a prática: o diário reflexivo e o estudo de caso. Eles têm possibilitado novas reflexões sobre as práticas existentes e a possibilidade de construção de uma clínica ampliada. Acreditamos que a Residência Multiprofissional possa ser uma ótima possibilidade de consolidarmos a atuação da TO em contextos hospitalares. Não apenas pela chance de formação e capacitação de novos profissionais para o mercado, mas também de fazermos uma releitura de nossas práticas e contribuir para a construção de um modelo de atenção mais integral. Entretanto, nenhum instrumento ou metodologia é mágico ou transformador por si só, depende de como o utilizemos. Portanto isto não está posto, tem que ser construído por nós.
\end{abstract}

Palavras chave: Terapia Ocupacional, Hospital, Especialização, Prática Profissional.

\section{Occupational Therapy in health care contexts: possibilities and challenges of multidisciplinary residency}

\begin{abstract}
This article is the result of a presentation at the Symposium of Occupational Therapy in Hospital Settings on the subject of graduate studies in the process of training and research in occupational therapy in hospital settings. The multi-professional residency was the main focus of this research. As it is a new experience in terms of occupational therapy, the impact it can have not only on the training of new professionals, but also in the practice of experienced ones was considered. While it broadens opportunities on the one hand, on the other hand, it challenges and makes us reflect about what we want: reproduce existing models of practice or consider new ones? To this end, two instruments used with residents to promote reflection on practice were questioned: the reflective journal and the case study. They have allowed for further reflection on existing practices and the possibility of building an extended clinic. It is believed that multidisciplinary residency can provide an important opportunity to consolidate the role of OT in hospital settings; not only for the chance to educate and train new professionals to the market, but also to review our practices and contribute to a more comprehensive model of care. However, no method or instrument is able to promote changes on its own; it depends on how it is used. This is not set up, though; it must be built.
\end{abstract}

Keywords: Occupational Therapy, Hospital, Specialization, Professional Practice. 


\section{Introdução}

Enquanto profissionais de saúde, nós terapeutas ocupacionais vimos acompanhando desde a constituição de 1988, que resultou dentre outros na criação do Sistema Único de Saúde (SUS), propostas de mudança na formaçáo dos profissionais de saúde. Nascimento e Oliveira (2010) apontam que essa discussão ganhou outro fôlego quando o próprio Ministério da Saúde (MS) passou a nortear sobre a formação dos profissionais de saúde com competências para atender às necessidades do SUS, através de estratégias como as Diretrizes Curriculares Nacionais para os diversos cursos na área da saúde e na modalidade lato sensu, os programas de Residência Multiprofissional. O que de forma geral vem sendo cada vez mais valorizado é o papel das instituiçóes de saúde na formaçáo profissional.

Não há como realizar uma discussão sobre o tema Residência enquanto modalidade de ensino na área de saúde sem nos reportamos inicialmente à Residência Médica. Foi dessa experiência que veio a idéia base para formar e capacitar profissionais na prática, desenvolvendo habilidades e competências específicas em determinado contexto ou área. Reconhecida como uma especialização, a residência médica também está historicamente no cenário brasileiro, fortemente associada a um modo de fazer hegemônico ligado a especialidades. Entretanto, a Residência Multiprofissional, táo acalentada e desejada por diversas categorias, aqui incluindo a Terapia Ocupacional (TO), procura trazer outros sentidos (DALLEGRAVE; KRUSE, 2009).

A Residência Multiprofissional foi concebida como uma alternativa capaz de promover mudanças na prática assistencial em saúde, favorecer o trabalho em equipe, facilitar as trocas efetivas de saberes e práticas. Dessa maneira, espera-se possibilitar a construção de um novo modo de realizar o cuidado à saúde da população, pelos profissionais das diferentes áreas da saúde tendo como base os princípios e diretrizes do SUS (NASCIMENTO; OLIVEIRA, 2010).

Pensando então essa realidade nos espaços hospitalares, área em que a TO apesar de já ter inúmeras inserçôes, é bastante diversa e vem cada vez mais procurando realizar reflexóes como apontam De Carlo, Bartalotti e Palm (2004) que utilizam o termo "contextos hospitalares" e Galheigo (2007) que se refere a "práticas hospitalares", é que propomos alguns questionamentos. Reiteramos que nossa intenção não é apontar um único caminho ou resposta, mas fomentar uma discussão e reflexão sobre uma experiência que, na nossa perspectiva, pode ter repercussôes muito maiores do que apenas na formação de novos profissionais.

\section{Refletindo sobre a residência multiprofissional}

Em primeiro lugar é importante destacar que, sem dúvida garantir uma vaga para nossa categoria nos programas de residência multiprofissional é um avanço político, mas requer a participação intensa de todos os profissionais dos serviços. E esse é um ponto importante, pois, mesmo aqueles que náo se configuram como coordenadores de área, tutores ou preceptores, estarão envolvidos, uma vez que os residentes transitam por todo o espaço hospitalar, observando e interagindo com os profissionais de forma geral.

Outro questionamento necessário é: o que entendemos por um período de residência? Pode parecer óbvio, mas é fundamental que possamos ver o residente como alguém em processo de formação intensivo (e na apenas como simples mão de obra), o que gera desdobramentos como responsabilidade dos tutores e preceptores não apenas sobre montar grade de atividades e canais teóricos, mas também estar presente e próximo ao campo de ação dos residentes.

Certamente dá muito trabalho montar uma programação de residência, dar tutoria e preceptoria. Implica em disponibilidade - interna e de tempo; disposição para estudar, manter-se atualizado e ler - como vamos selecionar material para o outro se não conhecemos o conteúdo; questionar-se e ser questionado. Implica também em pensar a inserção da TO nos contextos hospitalares para além de nossa prática pessoal.

É fundamental nesse momento em que estamos no início de inúmeros programas de Residência Multiprofissional em todo o Brasil que contemplam a área de TO, que possamos refletir sobre o que pretendemos. Vamos reproduzir modelos por vezes cristalizados e que criticamos ou aproveitar para construir novas propostas, num desafio de parceria com outras áreas? Como abrir novos campos, construir novas parcerias, pensar novos olhares?

Que espaço queremos ocupar através das Residências - uma das questôes que escutamos com alguma recorrência é a de que não existem terapeutas ocupacionais suficientes para darem conta de todas as demandas na saúde (isso sem falar nas outras áreas de atuação como social e educação). Em relação ao espaço hospitalar onde queremos ampliar e legitimar nossa atuação, não seria a Residência uma das maneiras de formar profissionais 
de qualidade, com expertise mais acentuada nesses contextos (extremamente diversificados, mas com necessidades específicas)?

Certamente nos interessa participar de uma discussão ampliada e atual de saúde, ou nos manteremos nas beiradas da reabilitação (os encaminhamentos continuam a ser feitos por médicos, baseados apenas em critérios de recuperação de funcionalidade). Como discute Galheigo (2007) é imperioso questionar sobre o diálogo estabelecido entre a TO e a atenção hospitalar, os diferentes dispositivos de atenção à saúde e principalmente ao processo de produção de saúde.

A saúde tem configuraçôes diferenciadas em cada país, pois existe um forte componente cultural nela, entretanto a cultura é construída por todos nós, indivíduos e grupos. $\mathrm{Na}$ TO formamos um grupo (o que não significa que seja homogêneo) e como tal definimos através de nossas açóes com que racionalidade nos afinamos mais, o que entendemos por saúde e doença.

Por conta disto, a necessidade de refletir sobre nossa própria prática, não deve ser algo apenas individual de cada profissional, mas também dos serviços e instituiçôes de saúde. Uma das maneiras de refletirmos é realizar estudos e pesquisas sobre nossas práticas. Sem dúvida atualmente esse é um dos grandes desafios a que todos os profissionais ligados à área acadêmica são cobrados. Mas existem também outros mecanismos que podemos utilizar para inserir a reflexão crítica no processo de Residência. Um deles é refletir sobre os instrumentos que utilizamos.

Marcolino e Mizukami (2008) destacam a importância do profissional investigar sua prática através de um processo reflexivo, sabendo que essa prática não é composta apenas pela aplicação de técnicas. A prática cotidiana envolve também o conhecimento produzido pelo profissional a partir de sua vivência de situaçôes singulares e complexas, onde utiliza o chamado conhecimento implícito ou tácito (SCHÖN, 1983 apud MARCOLINO; MIZUKAMI, 2008). Essas autoras discutem ainda que o processo de reflexão alia pensamento e ação, exigindo uma atividade diferente da feita rotineiramente, sendo um importante componente do processo de construção do conhecimento prático profissional.

Nesse sentido, trazemos como exemplo (sem qualquer pretensão de invenção da roda) dois instrumentos que utilizamos no Programa de Residência Multiprofissional na área de crianças e adolescentes cronicamente adoecidos e que possibilitam esse exercício reflexivo não apenas entre os residentes, mas na equipe de saúde como um todo: o diário reflexivo e o estudo de caso.

\section{Sobre o diário reflexivo e o estudo de caso}

O diário reflexivo como o próprio nome diz, é uma escrita diária que se pretende reflexiva e não meramente descritiva sobre todas as atividades realizadas (não apenas as assistenciais). Este material é trabalhado pelos tutores, tanto os específicos de cada área (que leem este material), quanto pelo grupo dos demais residentes e coordenação geral da Residência Multiprofissional, através de reuniôes semanais.

Desse material saem tanto orientaçóes de conduta prática, quanto eixos para discussão em grupo entre os residentes das diferentes áreas (sempre com tutores) além de temas de aulas que complementam a grade teórica. Desta forma, questôes diversas, que permeiam o universo da rotina dos profissionais de saúde em um hospital, como morte, trabalho em equipe ou mesmo a especificidade de determinadas doenças ou condutas clínicas são vistas na prática e em sua interface teórico-conceitual.

O estudo de caso na área da saúde é um procedimento geralmente utilizado na clínica, com o objetivo de compreender a complexidade do quadro apresentado pelo paciente e planejar a intervenção. Assim sendo, deve integrar as diferentes técnicas e áreas do conhecimento, de forma a favorecer a singularidade de cada indivíduo e situação, o que implica na realizaçáo de uma observação direta e cuidadosa, além da atenção aos diferentes significados encontrados nas açóes de cada indivíduo (PEREIRA; GODOY; TERÇARIOL, 2009).

No exemplo prático que tomamos, o caso estudado parte sempre de uma escolha dos próprios residentes. Todas as áreas participam mesmo aquelas que não atendam diretamente aquele usuário. Nesse caso, irão conhecê-lo pessoalmente, inteirar-se do caso, ler o prontuário e preparar uma reflexão sobre sua contribuição pensando possibilidades de conduta ou o seu olhar reflexivo sobre o caso.

Este instrumento tem sido particularmente potente, pois o processo de construção do caso é sempre coletivo, realizando algo que muitas vezes os serviços não fazem ou fazem pouco, a interlocução conjunta. Essa interlocução aponta para a possibilidade concreta de pensar-se em uma clínica ampliada (e não apenas interconsultas com opiniōes isoladas e dicotomizadas, tal qual linha de montagem). 
Por clínica ampliada nos referimos a uma construção do cuidado diferenciada. Isso implica na ampliação do objeto de trabalho de cada área, não apenas valorizando os aspectos orgânicos e biológicos, mas entendendo que qualquer quadro clínico ou doença refere-se a um sujeito específico, com todas as suas particularidades. Significa também pensar a produção de saúde através de diversos meios além dos curativos, aí incluindo os preventivos, a reabilitação e os cuidados paliativos, além da possiblidade de ampliar a autonomia desses sujeitos (CAMPOS; AMARAL, 2007).

Acreditando que na TO dentro dos contextos hospitalares também almejamos essa autonomia por parte daqueles a quem atendemos e suas famílias, é imprescindível passar essa visão aos novos profissionais. È fundamental que possam valorizar a capacidade desses usuários compreenderem melhor o que se passa com eles e ampliarem sua participação no processo saúde/doença. A clínica ampliada não existe sem a participação ativa dos diversos saberes e olhares.

\section{Considerações finais}

Campos (1999) já discute a questáo da formação dos profissionais de saúde a bastante tempo, tendo inicialmente lançado suas reflexôes sobre a formação médica e as estendido para as outras áreas da saúde, aí nominalmente incluída a TO. Aproveitando suas idéias e ampliando a importância da formação profissional para além da graduação, é que apontamos para a responsabilidade de estarmos atentos para uma reorientação das responsabilidades e práticas da TO através também das Residências Multiprofissionais.

Dessa forma, acreditamos que poderemos efetivamente contribuir através de nossa conduta, para a construçáo de uma maior autonomia dos sujeitos (profissionais e usuários) e consolidação efetiva de nossas práticas, já que rompemos com um modelo hegemônico de valorização de um único saber. Passamos muito tempo, ansiando por possibilidades de expansão e reconhecimento da TO no cenário da saúde. Cada vez mais espaços vêm sendo conquistados pela categoria e obviamente a responsabilidade também aumenta, assim como as discussões e desafios. Agora é hora de protagonismo, é o momento de construir novas inserções. Pensando sempre que podemos escolher como queremos ocupar novos papéis e sermos reconhecidos.

A Residência Multiprofissional pode ser uma ótima possibilidade de consolidarmos a atuação da $\mathrm{TO}$ em contextos hospitalares. Náo apenas pela chance de formação e capacitação de novos profissionais para o mercado, mas também de fazermos uma releitura de nossas práticas e contribuir para a construção de um modelo de atenção mais integral. Entretanto, nenhum instrumento ou metodologia é mágico ou transformador por si só, depende de como o utilizemos. Portanto isto não está posto, tem que ser construído por nós.

\section{Referências}

CAMPOS, G. W. S. Educação médica, hospitais universitários e o Sistema Único de Saúde. Cadernos de Saúde Pública, Rio de Janeiro, v. 15, n. 1, p. 187-193, jan/mar. 1999. http://dx.doi.org/10.1590/ S0102-311X1999000100019

CAMPOS, G. W. S.; AMARAL, M. A. A clínica ampliada e compartilhada, a gestão democrática e redes de atençáo como referenciais teórico-operacionais para a reforma do hospital. Ciência e Saúde Coletiva, Rio de Janeiro, v. 12, n. 4, p. 849-859, 2007. http://dx.doi.org/10.1590/ S1413-81232007000400007

DALLEGRAVE, D.; KRUSE, M. H. L. No olho do furacão, na ilha da fantasia: a invenção da residência multiprofissional em saúde. Interface, Botucatu, v. 13, n. 28, p. 213-237, jan./mar. 2009. http://dx.doi.org/10.1590/ S1414-32832009000100018

DE CARLO, M. M. P.; BARTALOTTI, C. C.; PALM, R. C. M. A Terapia ocupacional em reabilitação física e contextos hospitalares: fundamentos para a prática. In: DE CARLO, M. M. P.; LUZO M.C. M. Terapia Ocupacional: reabilitação física e contextos hospitalares. São Paulo: Roca, 2004. p. 3-28.

GALHEIGO, S. M. Domínios e temáticas no campo das práticas hospitalares em terapia ocupacional: uma revisão da literatura brasileira de 1990 a 2006. Revista de Terapia Ocupacional da Universidade de São Paulo, São Paulo, v.18, n. 3, p. 113-121, set./dez. 2007.

MARCOLINO, T. Q.; MIZUKAMI, M. G. N. Narrativas, processos reflexivos e prática profissional: apontamentos para pesquisa e formação. Interface, Botucatu, v. 12, n. 26, p. 541-547, jul./set. 2008. http://dx.doi.org/10.1590/ S1414-32832008000300007

NASCIMENTO, D. D. G.; OLIVEIRA, M. A. C. Competências profissionais e o processo de formaçáo na residência multiprofissional em Saúde da Família. Saúde e Sociedade, São Paulo, v. 19, n. 4, p. 814-827, out./dez. 2010. http://dx.doi.org/10.1590/S0104-12902010000400009 PEREIRA, L. T. K.; GODOY, D. M. A.; TERÇARIOL, D. Estudo de caso como procedimento de pesquisa científica: reflexão a partir da clínica fonoaudiológica. Psicologia: Reflexão e Crítica, Porto Alegre, v. 22, n. 3, p. 422-429, 2009. http://dx.doi.org/10.1590/ S0102-79722009000300013 